\section{EDITORIAL NEWS.}

THE Autumn Programme of the Seventeenth Annual Series of Chadwick Public Lectures opened on Tuesday, October I5 at 8.I5 p.m. at the Institution of Mechanical Engineers, Storey's Gate, Westminster, with the first of two lectures (illustrated by lantern slides) on "Sewage and Sewage Disposal." $\mathrm{Mr}$. A. J. Martin, M.Inst.C.E., was the Lecturer, and the Chairman Mr. W. Addington Willis, C.B.E., LL.B., a Chadwick Trustee. Mr. Martin's second lecture was two nights later, Thursday, October I7, at the same hour and place, when Sir George Humphreys, Chief Engineer of the London County Council and Chadwick Trustee, presided.

Special interest will attach to the next short course, as the lecturer, Professor. J: Boeke, of Utrecht University, who comes to England from Holland on the invitation of the Chadwick Trustees, has a world reputation for his knowledge of histology. He speaks English fluently, and cannot fail to charm and enlighten both medical and non-medical hearers with his discourses on "The Tissues in Youth and Age" and "The Nervous System in Relation to Health." Such subjects have a more than international interest. . They are human and vital to us all.

Professor Boeke's lectures will be given at the British Medical Association, Tavistock Square on Tuesday, October 29 and Friday, November I, at 5 I5 p.m. Sir William J. Collins, Chairman of the Chadwick Trustees, will preside on the Tuesday, and Sir James Crichton Browne, Chadwick Trustee, on the Friday.

"The Causes of Cancer" is the title given by Professur A. E. Boycott, D.M., F.R.S., to the Chadwick Lecture, in which he will deal with that troublous and devastating disease in its relation to practical hygiene and the smoke problem.
This lecture will be at the Royal Society of Arts, Friday, November 22, at 8 p.m.

Again Sir William Collins will preside, as he will also for a lecture in the Inner Temple Hall early in December on "Public Health Law and Administration," intro. duced by the Local Government Act, 1929, which Mr. William A. Robson, B.Sc., Ph.D., Barrister-at-Law, will deliver.

Admission to these lectures is free and no tickets are required.

A party of over roo Jugoslav doctors, now visiting London, assembled on Saturday morning, October I9, in the Barnes Hall of the Royal Society of Medicine. Short addresses of welcome were given by Sir William Hale-White and Sir James Berry on behalf of the Fellowship of Medicine and the Jugoslav Society of Great. Britain respectively. Dr. Richard Burian, Professor of Physiology at Belgrade University, speaking in excellent English, made the following reply :-

"Sir William Hale-White, Ladies and Gentlemen,-When we decided to visit this great city we were not only animated by the desire to see the vital centre of a large part of the terrestrial globe, and the capital of a nation which has contributed immensely to the civilization of the world, but we wanted above all to have contact with the leaders of English medical science and the British medical service.

"We Jugoslavs are conscious of the fact that we have; individually and as a whole, very much to learn from the great British nation. Only some months ago our excellent Professor Bogdon Popovic gave us a beautiful lecture on this subject. This, the contact with you, is of inestimable value to the Jugoslav medical men, even as far as medicine is not concerned.

"However, its principal importance is on medical grounds. Our two medical Faculties, of Belgrade and of Zagreb, are young and not quite settled, being founded in a country worn out by the war, and without 
proper traditions in medical teaching. But we are earnestly $\epsilon$ ndeavouring to raise teaching and research, theory and practice, to a level equal to that existing in other civilized countries, and for these efforts of ours nothing can be more helpful than close relations with the headquarters of British medicine.

"Therefore, we hope that these relations will become more and more close and cordial, and that we shall have the pleasure of welcoming British medical men, also with us, although our medical institutions are only in the beginning of their development. A few days ago we had the privilege of seeing at Belgrade Dr. Findlay, the excellent Professor of Pediatrics of Glasgow, and to listen to his most interesting lecture. We should be happy if other representatives of British medical science would follow this example.

"In any case the hours which we have the honour to spend with you will remain a remarkable date in the history of the approach of our young medical schools to those of this great country. Most sincerely, therefore, do I desire to thank in the name of this party and of the Jugoslav medical men in general: the Royal Snciety of Medicine, and the Fellowship of Medicine, and the Jugoslav Society, for their hospitality and most interesting film shown to us, and Sir William Hale-White and Sir James Berry for their very kind words of welcome."

Professor Ainsworth Davis showed the Canti film of the cultivation of healthy and cancerous tissues under the microscope and the action of radium emanation upon them. This film had been kindly lent by the British Empire Cancer Campaign and was greatly appreciated by the audience.

\section{COR RESPON DENCE.}

TO THE EDITOR OF THE " POST-GRADUATE MEDICAL JOURNAI..

SIR,-I read with great interest the artic by Dr. Lucas on the climate in the Canar\% Islands.

I should be grateful if any of your readers could tell me whether a consumptive patient who also has bronchitis is suitable for a winter in the Swiss Alps. I have found that asthmatics improve when sent to hige altitudes, and wondered if a bronchitie would get the same benefit or whether thiss should be taken as a contra-indication, and it is better to send such patients to a plach where the climate is just the opposite namely, warm and damp.

$$
\begin{aligned}
& \text { I am, } \\
& \text { Yours faithfully, }
\end{aligned}
$$

\section{POST-GRADUATE NEWS.}

Six special courses will take place during the current month. On successive Fridays, from November I to November 22, Pros fessor Dame Louise Mcllroy, D.B.E., wif give a course of four demonstrations of antenatal diagnosis and treatment at the Royal Free Hospital, at 5 p.m. The course is limited to ten, and the fee is $f_{\mathrm{I}} \mathrm{Is}$.

From November 4 to November 23 there will be a special course in medicine, surger and gynæcology at the Royal Waterlo. Hospital for Women and Children. Lectures demonstrations will be given in the Wardis and Out-patient Departments. Specian reference will be made to the following subjects: Endocrine deficiency, diseases of the blood, thyroid, respiratory organs stomach, cardiac affections, \&c. The course will occupy the greater part of the day, and the fee is $£ 33$ s. 